\title{
Perspectivas de Liberdade e Igualdade na "Revolução" Baiana de 1798
}

\section{Perspectivas de Libertad e Igualdad en la "Revolución" Baiana de 1798}

\author{
Ricardo Antonio Souza Mendes ${ }^{1}$ \\ Universidade do Estado do Rio de Janeiro (Brasil)
}

ORCID: https://orcid.org/0000-0001-9817-9325

Recibido: 27-07-2020

Aceptado: 10-11-2020

\section{Resumo}

Um dos movimentos sociais antimetropolitanos de maior pluralidade social ao longo do período colonial, a Conjuração Baiana de 1798, caracterizou-se pela diversidade de concepções em torno das ideias de Liberdade e Igualdade. A abordagem do movimento aponta para a eficácia com que as elites coloniais canalizaram as contradições internas à sociedade baiana na direção de um antagonismo que colocava as causas de todos os males no domínio português. Analisando documentos elaborados ou difundidos pelos participantes - tais como as Décimas à Liberdade e Igualdade e os denominados "Pasquins Sediciosos"-, ou mesmo o material produzido pela repressão metropolitana-fundamentalmente os "Autos de Devassa"-, buscou-se mapear as diferentes concepções de Liberdade e Igualdade apresentadas pelos partícipes da Conjura em fins do século XVIII no espaço colonial.

Palavras-chave: Bahia Colonial, 1798, Revolução Baiana, Liberdade e Igualdade.

\footnotetext{
${ }^{1}$ (rasmric5@gmail.com) Professor Associado de História da América no Departamento de História da Universidade do Estado do Rio de Janeiro (UERJ). Possui mestrado em História Social pela Universidade Federal do Rio de Janeiro (UFRJ-1996), doutorado em História pela Universidade Federal Fluminense (UFF - 2003) e pós-doutorado em História da América pela Universidade do Estado do Rio de Janeiro (UERJ - 2008). Desde 2015 é Coordenador do curso de Doutorado do Programa de Pós-Graduação em História Política (PPGH) da Universidade do Estado do Rio de Janeiro (UERJ). Autor do artigo O medo francês. Métis (UCS), v. 5, p. 101-120, 2006 e do livro, ainda no prelo, intitulado A inconfidencia Baiana de 1798 - um projeto de Nação Possível a ser publicado em 2021 pela Editora Metanoia.
} 


\section{Abstract}

One of the most plurality anti-metropolitan social movements throughout the colonial period, the Conjuration of Bahia in 1798 was characterized by the diversity of conceptions around the ideas of Freedom and Equality. The movement's approach points to the effectiveness which colonial elites channelling contradictions within Bahian society towards an antagonism that put the causes of all woes in the Portuguese domain. Analyzing documents prepared or disseminated by the participants -such as the Tenths to Freedom and Equality and the so-called "Pasquins Sediciosos"- or even material produced by the metropolitan repression -fundamentally the "Autos de Devassa"- we sought to map the different conceptions of Freedom and Equality presented by the participants of Conjura in the late 18th century in the colonial space.

Key-words: Colonial Bahia, 1798, Bahia Revolution, Freedom and Equality.

\section{Introdução}

Movimento antimetropolitano ocorrido em fins do século XVIII, a "Conjuração" Baiana de 1798, também denominada de "Revolta dos Alfaiates", junto com a "Conjuração" Mineira de 1789, a "Conjuração" do Rio de Janeiro de 1794 e a "Conjura" Pernambucana de 1801 compõem o quadro de manifestações de contestação ao domínio metropolitano. Todos os eventos assinalados acima foram abortados em seu nascedouro evitando, assim, que a Coroa Portuguesa se defrontasse com uma ação mais efetiva de ruptura antes de 1817, quando observa-se o desencadeamento da Revolução Pernambucana.

Com o envolvimento de segmentos sociais e profissionais os mais diversificados, as articulações de 1798 caracterizaram-se pela participação de negros e pardos, vários deles alfaiates, outros soldados, ou ainda soldadosalfaiates. Pode ser assinalado, igualmente, o envolvimento de brancos pobres -alguns alijados do sistema de produção, outros militares-, bem como de brancos da elite intelectual e econômica da América Portuguesa.

Isso, por si só se apresenta como um indício da existência de um projeto significativamente rico a colaborar para o envolvimento de grupos tão variados. As mobilizações em questão que proporcionaram a tentativa de revolta colonial ocorreram na cidade de Salvador e seu recôncavo, mais especificamente entre 1797 e 1798 . O contexto de seu aparecimento foi marcado por diversos fatores. Além da assinalada crise do "sistema colonial", o momento marca também uma tensão endêmica do sistema escravista, bem como o impacto da chegada de uma nova visão de mundo, o Iluminismo. 
$\mathrm{Na}$ análise das ideias propagadas pelo movimento utilizo documentos elaborados ou difundidos pelos participantes. Um dos principais materiais produzidos intitula-se "Décimas à Liberdade e Igualdade". Sua importância pode ser observada pelo fato de que boa parte dos participantes tinham decorado sua composição, aspecto extremamente relevante em uma sociedade marcada profundamente pela oralidade da comunicação.

A autoria destes versos é controversa. Segundo Domingos da Silva Lisboa $^{3}$, junto com quem foram encontrados esses documentos, chegaram as suas mãos através do Cônego Salvador Pires de Carvalho Albuquerque ${ }^{4}$ ou eram do seu tempo. Para Lucas Dantas do Amorim Torres ${ }^{5}$, a autoria seria do professor de Gramática Latina Francisco Muniz Barreto do Aragão, que residia na época da Devassa em Rio das Contas. Já Manoel Faustino ${ }^{6}$ ignorava quem fosse o autor ou autores, embora as tivesse copiado de Fortunato da Veiga, que alegara ignorar a existência do referido. O próprio Francisco Muniz afirmava que as tinha copiado de umas anotações feitas por um homem de Pernambuco chamado José Porfírio, "praticante" de navios, o qual, por sua vez, lhe havia afirmado que o autor era um religioso do Convento do Carmo?.

Outro tipo de documentação aqui utilizada foi denominada pela repressão metropolitana como "Pasquins" ou "Boletins Sediciosos". Série de comunicados espalhados pela cidade de Salvador entre os dias 12 e 22 de agosto de 1798, instavam a população a manifestarem-se contra a Coroa Portuguesa, o que ocasionou a instauração de investigações por parte das autoridades metropolitanas. Doze "Boletins" chegaram preservados até a atualidade. ${ }^{8}$ Contudo, a existência de pelo menos mais quatro boletins foram relatadas por diversas testemunhas. Dois desses defendiam que o fim dessa escravidão seria obtido pela "Revolução". Foi a propagação desse conjunto de Boletins que acabou por desencadear o inquérito para identificar o "gravíssimo" crime de Lesa Majestade.

${ }^{2}$ A versão utilizada das Décimas à extraída de Tavares, Luís Henrique. História da Sedição Intentada na Bahia de 1798. São Paulo: Ed. Pioneira/ Brasília: Instituto Nacional do Livro, 1975, p. 89.

${ }^{3}$ Domingos da Silva Lisboa, militar, pardo liberto. Arrolado no inquérito como participantes da Conjuração.

${ }^{4}$ Ex-padre da Companhia de Jesus, era membro de abastada família de proprietários de engenhos.

${ }_{5}^{5}$ Pardo liberto, marceneiro nas horas em que não estava no quartel, era soldado do regimento de artilharia. Foi identificado pelo inquérito estabelecido pela Coroa Portuguesa como uma das principais lideranças do movimento baiano, foi condenado à forca e esquartejado em praça pública.

${ }^{6}$ Manoel Faustino dos Santos Lira, pardo liberto nascido na cidade de Santo Amaro. Considerado também como um dos participantes do movimento pelo inquérito estabelecido por ordem da Coroa Portuguesa.

${ }^{7}$ Os Autos de Devassa concluíram na acusação de Muniz Barreto que este não era o autor, porém, não identificando quem o seria.

${ }^{8}$ Biblioteca Nacional, Seção de Manuscritos, I - 28, 23 / no. 1-12, cópia dos originais.

${ }^{9}$ Quanto à autoria dos Boletins, inicialmente, foi acusado Domingos da Silva Lisboa, pardo liberto, soldado e advogado de suplicantes. Contudo, após essa prisão, mais dois boletins foram afixados em partes da Cidade de Salvador. Isso ocasionou na sua libertação e a prisão de Luís Gonzaga das Virgens e Veiga, militar e pardo liberto.

Araucaria. Revista Iberoamericana de Filosofia, Política, Humanidades y Relaciones Internacionales, año $23, \mathrm{n}^{\circ} 46$. Primer cuatrimestre de 2021. Pp. 103-124. ISSN 1575-6823 e-ISSN 2340-2199 https://dx.doi.org/10.12795/araucaria.2021.i46.06 
Denominado na época por "Auto de Devassa", esse material também foi abordado. Apesar de originarem-se no ato mesmo da repressão ao movimento de 1798, os Autos encontraram seu significado de utilização quando confrontados com as "Décimas" e com os "Boletins". Dois Autos de Devassa foram estabelecidos naquele momento. O primeiro, para a identificação da autoria dos "Boletins" ou "Pasquins" Sediciosos. Já o segundo, objetivava identificar os efetivos envolvidos na trama "sediciosa" de instauração de uma "República Bahianense"10.

É com base nesse material que buscou-se delimitar a existência de uma cultura revolucionária em germinação na Bahia, em fins do século XVIII, relacionada com a compreensão que seus participantes possuíam em relação às ideias de "liberdade" e "igualdade". Referências centrais do ideário iluminista Europeu, essas ideias foram reconfiguradas na medida em que eram propagadas na América Portuguesa.

Por certo trata-se de indícios, visto que não é uma documentação extremamente vasta. Contudo, Guinsburg aponta a possibilidade de identificação de uma realidade mais profunda através de pequenos sinais. De outro lado, em suas análises sobre Mennochio, esse autor também se utiliza de documentos oriundos dos responsáveis pela ordem para analisar as ideias do moleiro ${ }^{11}$.

A semelhança deste tipo de investigação é com o método de análise da semiótica médica ou da sintomatologia. Segundo o autor, o caçador "pode ter sido o primeiro a contar uma história, porque apenas caçando eles sabiam como interpretar uma sequência corrente de eventos a partir de obscuros (e quase imperceptíveis) sinais deixados pela preza" 12 .

Ainda tendo Guinzburg como referência, a cultura deve ser compreendida como "um feixe de possibilidades latentes" que depende da realidade social em que se situam os indivíduos. Em grande medida, essa perspectiva apresenta-se como referência explicativa para a diversidade semântica das ideias de liberdade e igualdade, não apenas entre europeus e "baianos", mas também dentre os próprios inconfidentes. Essas questões, aliadas a outro conceito trabalhado pelo autor $-\mathrm{o}$ de circularidade cultural-, contribuem para o entendimento de que, apesar dessa diversidade de perspectivas, em última instância acabou por predominar a noção oriunda das elites para explicar as mazelas que afetavam o mundo colonial baiano: o domínio metropolitano. Nesse sentido, ainda que existisse uma variedade de concepções, foi a perspectiva das elites que acabou por se sobrepor.

${ }^{10}$ Quanto à documentação relativa às Devassas utilizo a edição publicada pela Biblioteca Nacional intitulada A Inconfidência da Bahia: devassas e sequestros. Rio de Janeiro: Officinas Graphicas da Biblioteca Nacional, 1931, 2 vol. Esse material foi extraído dos volumes XLIII, XLIV e XLV dos Anaes da Biblioteca Nacional.

${ }^{11}$ Guinsburg, Carlo. O Queijo e os Vermes - cotidiano e as ideias de um moleiro perseguido pela inquisição. Rio de Janeiro: Cia das Letras, 1987.

12 "Chaves do Mistério: Morelli, Freud e Sherlock Holmes", in: Eco, Umberto e Sebeok, Thomas A.(org). O Signo deTrês. São Paulo: Ed. Perspectiva, 1991, p. 100.

Araucaria. Revista Iberoamericana de Filosofia, Politica, Humanidades y Relaciones Internacionales, año $23, \mathrm{n}^{\circ} 46$. Primer cuatrimestre de 2021. Pp. 103-124. ISSN 1575-6823 e-ISSN 2340-2199 https://dx.doi.org/10.12795/araucaria.2021.i46.06 
Levando-se em consideração que estes documentos foram produzidos por elementos contrários ao sistema de dominação vigente, qualquer registro que espelhasse suas ideias seria altamente incriminador. Como nos indica Thompson, é "desnecessário dizer que sempre haverá muitas coisas obscuras acerca de grupos engajados em atividades ilegais que tiveram o cuidado de deixar poucos traços registrados"13.

Esse é o caso da "Revolução" Baiana, que legou poucos documentos à posteridade. Movimento colonial que visava libertar a Bahia do jugo metropolitano, fruto de descontentamentos de vários tipos, tentou ser desencadeado após a prisão de Luís Gonzaga das Virgens e Veiga, sob a acusação de que ele seria o autor dos Boletins Sediciosos. Estavam temerosos de serem delatados por um dos principais participantes das reuniões marcadas por confabulações sobre as ideias francesas e a possibilidade de implantar a liberdade. Por isso, se mobilizaram.

O objetivo duplo - libertar Luís Gonzaga e iniciar o movimento com fins Republicanos- não se concretizou. Descobertos por várias delações feitas aos representantes metropolitanos, diversos indivíduos que dela participaram destruíram papeis incriminadores que estavam em sua posse. Contudo, ainda assim, torna-se viável a aproximação com o ideário que orientou segmentos que dela participaram com base na documentação aqui elencada.

\section{Revolução? Ideias de Liberdade e Igualdade no espaço colonial}

Nas análises realizadas nesse material observou-sequeideias de "Liberdade" e "Igualdade" encontraram um novo sentido na Capitania da Bahia, em fins do XVIII, provocado não por um empobrecimento ideológico dos agentes que as incorporaram, mas sim, devido à possibilidade de reinterpretação oriunda de uma realidade diferenciada. Como afirma Guinsburg, a cultura "oferece ao indivíduo um horizonte de possibilidades latentes - uma jaula flexível e invisível dentro da qual se exercita a liberdade condicionada de cada um"14.

A escolha desses termos deu-se por diversos fatores. O primeiro deles relaciona-se ao fato de que foram amplamente utilizados nos documentos diretamente produzidos pelos participantes do movimento. Nos Boletins Sediciosos, a palavra "livre" ou "Liberdade" está citada nada menos do que trinta e oito vezes, e a palavra "igual" ou "Igualdade" está presente nove vezes e sempre associada ao termo "Liberdade".

${ }^{13}$ Thompson, E. P.. A formação da Classe Operária Inglesa. - A Árvore da Liberdade. Rio de Janeiro: Ed. Paz e Terra, 1987, p.177.

${ }^{14}$ Guinsburg, Carlo. O Queijo e os Vermes - cotidiano e as ideias de um moleiro perseguido pela inquisição. Rio de Janeiro, Cia das Letras, 1987, p. 27.

Araucaria. Revista Iberoamericana de Filosofia, Política, Humanidades y Relaciones Internacionales, año $23, \mathrm{n}^{\circ} 46$. Primer cuatrimestre de 2021. Pp. 103-124. ISSN 1575-6823 e-ISSN 2340-2199 https://dx.doi.org/10.12795/araucaria.2021.i46.06 
O segundo motivo está no entendimento de que estes dois termos foram de tal importância para o movimento que a eles foi dedicado o verso intitulado "Décimas a Igualdade e Liberdade". Os versos assinalam a apologia aos termos em questão, indicada não apenas pela sua elaboração, mas pelo fato (identificado pela repressão) de que o mesmo foi decorado por diversos de seus participantes, tal como apontado pelos "Autos de Devassa"15.

Outro fator para a escolha se encontra na relação entre o movimento baiano e a Revolução Francesa. Citado por diversos estudiosos do movimento ${ }^{16}$, essa relação desdobra-se na influência da disseminação do Ideário Iluminista Francês por boa parte do mundo e, principalmente, pelas colônias americanas. Nesse momento apareceu e se consolidou uma nova concepção do termo Nação ${ }^{17}$, associada à tentativa de fundar uma nova ordem baseada em pressupostos diametralmente opostos aos da sociedade de Antigo Regime e, por isso, tão divulgados por aqueles interessados no rompimento da ordem. Essa nova concepção estava associada diretamente as ideias de liberdade e igualdade aqui assinaladas.

Por último, a escolha vincula-se com a preocupação apresentada pelos representantes metropolitanos quanto ao uso desses dois termos associado a novas ideias de caráter iluminista. Nas três denúncias do movimento, elaboradas por indivíduos convidados para dele participarem, um dos principais aspectos citados como "perniciosos" para o poder instituído foram as ideias de Igualdade e Liberdade. Esses termos também foram referidos nos documentos em que as ideias dos participantes se encontravam espelhadas de forma indireta ou modificada pela visão do agente repressor: os depoimentos dos Autos de Devassa. Isto vem a confirmar que as autoridades tinham como certo que a Liberdade e Igualdade defendidas pelos participantes da Conjura representavam uma proposta de nova ordem incompatível com o "Status Quo".

${ }^{15}$ Dentre os que haviam decorado as décimas os Autos identificaram Lucas Dantas do Amorim Torres, Manoel Faustino dos Santos Lira, Fortunato da Veiga, Domingos da Silva Lisboa e o próprio Muniz Barreto.. Julgando-se como correta a afirmativa desse último, ele teria reproduzido caligraficamente os versos em questão (que não seriam de sua autoria), o que apontaria para uma difusão e importância também dentre segmentos letrados da sociedade baiana.

${ }^{16}$ Dentre os autores que assinalam esse aspecto cito: Amaral, Braz. Os confederados do Partido da Liberdade. Salvador: Imp. Oficial, 1922; Matoso, Kátia de Queiroz. Presença francesa no movimento democrático baiano. Salvador: Ed. Itapuã, 1969; Mattos, Florisvaldo. A comunicação social na Revolução dos Alfaiates. Bahia: Imp. Oficial, 1974. (Coleção Estudos Baianos); Motta, Carlos Guilherme. Ideia de revolução no Brasil: 1789-1801. São Paulo: Ed. Cortez, 1989; Ruy, Afonso. A primeira revolução social brasileira. Salvador: Ed. Progresso, 1995; Jancsó, Itsvan. Na Bahia, Contra o Império: história do ensaio de sedição de 1798. São Paulo: Ed. Hucitec, 1996; e Tavares, Luís Henrique. Da Sedição de 1798 à Revolta de 1824 na Bahia. Salvador: EDUFBA; São Paulo: Unesp, 2003.

17 Ver: Anderson, Benedict. Nação e Consciencia Nacional. São Paulo, Ática, 1989; e Hobsbawn., Hobsbawn, Eric. Nações e nacionalismo desde 1780: programa, mito e realidade. Rio de Janeiro: Editora Paz e Terra, 1990. 
Essas ideias foram analisadas em duas etapas. A primeira, associada à documentação produzida pelos revoltosos - as "Décimas" e os "Boletins Sediciosos". Essa primeira etapa está subdividida em três tópicos: "Ares de um "novo tempo", "Fim do jugo colonial e igualdade de relações comerciais" e "Libertação dos Escravos e Igualdade Étnica". Já a segunda etapa tem por foco a abordagem dos "Autos de Devassa".

Ares de um "novo tempo"

$O$ vós que nacesteis para sereis livres, e para gozares dos bons efeitos da Liberdade [sic]

Boletim número 3

Se a cauza motriz dos entes

Tem as mesmas sençações

Mesmos orgãos e precizões;

Dados a todos os viventes

Se a qualquer suficienes

meios da necessidade

Remir Deus com equidade,

Logo são impercretiveis

E de Deus Leis infaliveis

Igualdade e Liberdade. [sic]

Primeiro verso das Décimas à Igualdade e Liberdade

Embora abordado poucas vezes, a apresentação por parte dos sediciosos sobre os motivos que os faziam acreditar na ocorrência de um novo tempo era um elemento de suma importância. Com base nessa convicção, os revoltosos procuraram a justificativa ideológica para a transformação da realidade. Estes motivos estavam fundados não apenas numa mera racionalização do mundo, mas numa mistura de racionalismo com o resgate de alguns princípios religiosos das primeiras comunidades cristãs, tais como o princípio da Igualdade estabelecida por "Deus". Nessa concepção, todos seriam iguais, visto possuírem mesma "causa motriz", mesmos "órgãos" e "precisões". Sendo assim, criados e regidos pelas mesmas leis divinas. Era a mensagem passada também quando observado o primeiro verso das "Décimas", onde o autor apontou que se "a qualquer suficientes meios da necessidade Remir deu com equidade". Para suprir suas necessidades, "Deus" teria dado a todos os homens os mesmos instrumentos.

Ao mesmo tempo em que essa igualdade de condições estabelecidas na "criação" teria sido concebida por princípios divinos, "Deus", na ótica dos sediciosos, também teria proporcionado a todos a liberdade necessária para que estas condições fossem atendidas. Somente diante de uma liberdade que abarcasse a todos os "entes" é que qualquer homem teria a sua disposição as iguais condições de atender as suas necessidades. Nesse momento, percebe-se a 
primeira relação estabelecida entre "Igualdade" e "Liberdade". Era necessário um estado de Liberdade para que todos tivessem Igualdade.

Esse primeiro verso das "Décimas" poderia ser lido, contudo, de outra forma. Liberdade e igualdade seriam leis infalíveis de "Deus" para que todos os seres pudessem suprir suas necessidades também de forma igual, já que todos teriam nascido dotados das mesmas qualificações. Porém, o mundo estava fundado numa ordem social diferente. A desigualdade havia sido estabelecida e, determinadas pessoas, já não tinham mais o poder de usufruir de sua Liberdade. Nas "Décimas" é assinalado que:

\footnotetext{
Se este dogma for seguido, e de todos respeitado, Fará bem aventurado Ao povo rude e polido. $\mathrm{E}$ assim que florescido Tem da América a Nação! Assim flutue o Pendão Dos Franceses que a imitaram Depois que afoitos entraram No sacrário da razão [...].

E ainda;

Quando os olhos dos Baianos

Estes quadros divizarem,

E longe de si lançarem

Mil despoticos tiranos

Quão felizes e soberanos,

Nas suas terras serão!

Oh doce comoção

Experimentam estas venturas,

Se elas bem que futuras

Preenchem meu coração. [sic]
}

Observe-se que o objetivo era o de conseguir para si, ou ainda para a sociedade Baiana, a realidade de igualdade e liberdade. E é o que anunciavam trechos de dois Boletins quando faziam a seguinte convocação: "Animai-vos Povo Bahiense que está para chegar o tempo feliz da nossa liberdade; o tempo em que todos seremos irmãos; o tempo em que todos seremos iguais" [sic]. A ocasião seria de mudanças, de um verdadeiro renascimento, de sair "do abismo da escravidão, para levantareis a Sagrada Bandeira da Liberdade".

Essa perspectiva vinha assinalada pela concepção de que se trataria de um “Tempo de ressurreição", de reinício de uma trajetória desvirtuada pelo homem. Momento no qual todos voltariam a ter o estado "feliz da nossa liberdade", 
"o tempo em que todos seremos iguais", momento da bem-aventurança, da felicidade e da soberania. Porém, não mais uma soberania baseada no Estado Nacional Monárquico, mas sim na "Liberdade" e "Igualdade". Haveria chegado o período "para vós defendereis a vossa Liberdade o dia da nossa revolução, da nossa Liberdade". A "nossa felicidade" estaria por chegar, e por isso convocavam todos para "sereis felis [sic] para sempre".

É justamente nessa promessa de fundação de um novo tempo onde pode ser identificado, dentre os participantes do movimento de 1798 ocorrido na Bahia, o seu caráter de transformação da sociedade, vinculando "liberdade" e "igualdade" através de um processo revolucionário. Para eles, a "revolução" seria o meio pelo qual seriam obtidas as novas condições. E para que fosse feita na Bahia "sua memorável revolução", objetivando a "liberdade e bem do povo", convocava-se, através dos Boletins, a toda a população. Era a intenção criar uma sociedade onde "não haverá diferença; só haverá liberdade, igualdade e fraternidade".

A revolução concretizaria o momento de "ressurreição" da escravidão, de "levantar a sagrada bandeira da Liberdade", o tempo em que todos seriam "irmãos", todos seriam "iguais". Porém, o movimento não era o fim, o destino a ser alcançado. Havia um projeto que estava em andamento, que era o de estabelecer de fato uma nova sociedade, uma "democracia" como afirmava o Boletim número 12 e, mesmo os elementos encarregados da repressão em seus relatos nos Autos de Devassa, embora o movimento ainda não estivesse em um estágio satisfatório para indicar mais especificamente a forma pela qual isto seria consolidado.

\section{Fim do jugo colonial e igualdade de relações comerciais}

Pode-se observar a presença de dois tipos básicos de Liberdade e Igualdade contidos tanto nos Boletins quanto nas Décimas. O primeiro deles, estreitamente vinculado com um projeto de libertação colonial, e um segundo, identificado a um projeto de libertação dos escravos. Nos boletins onde o autor procurou informar aos "Bahianos" o sentido que tinha "Igualdade" e "Liberdade", observa-se a associação mais marcante e explícita com o fim do jugo colonial, aliado a uma definição de igualdade de comércio e de condições de tratamento entre portugueses e "Bahianos". Observe-se, por exemplo, o seguinte trecho do Boletim Sedicioso número 3:

Ó vós Povo que nascesteis para seres livre e para gozares dos bons efeitos da Liberdade; Ó vós Póvos que viveis flagelados com o pleno poder do Indigno coroado, esse mesmo rei que vós criasteis; esse mesmo rei tirano é que se firma no trono para vos vexar; para vos receber e para vos maltratar (...). A Liberdade consiste no estado feliz, no estado do livre abatimento: a Liberdade é a doçura 
da vida, o descanso do homem com igual paralelo de uns para outros, finalmente

a Liberdade é o repouzo, é a bem aventurança do mundo. [sic].

O autor inicia sua narração apontando os aspectos que permeavam a sociedade colonial e que a tornariam desigual -0 abandono de seu povo por parte da Coroa Portuguesa-, justamente por ser este considerado pelo mesmo rei como um povo inferior e subjugado. As mazelas que teriam levado a exploração existente entre metrópole e colônia são imputadas todas à Coroa devido à forma de governo despótica que a caracterizava. Era colocada a vocação que todo povo teria para ser livre, tal qual o contido nas Décimas, para gozar dos bons efeitos da Liberdade, mas que no caso específico do povo baiano não seriam usufruídos, dado o flagelo de um regime controlado por um rei tirano.

Nesse sentido, o monarca não estaria sendo considerado imbuído de uma "missão divina" de governar. Esse atributo de governança seria conferido por seu povo, que imbuiu deste poder esse "mesmo rei que vós creasteis" [sic]. Agora, seria o "povo" o detentor de "desígnios divinos", invertendo assim a hierarquia das coisas dispostas no mundo já que, uma vez sendo o governo monárquico estabelecido pelo homem, poderia por ele ser eliminado.

A liberdade seria alcançada através do estado "livre do abatimento", através do "descanço [sic] do homem com igual paralelo de uns para outros", evitando-se a diferença de tratamento entre colonos e metropolitanos ou ainda as diferenças provocadas pela ordem imperial entre o centro e as partes. No Boletim de número 6 observa-se a reafirmação deste aspecto:

O Povo Bahinense Republicano para o futuro pretende mandar e quer que seja feita para o futuro a sua revolução nesta Cidade e seu termo para o que faz que seja ciente o comercio desta cidade e outrossim ordena que qualquer comissario, mercadores (mutilado) Cafés; Lavradores de mandiocas fabricantes de açucar, e tabacos hajão de ter todo o direito sobre as suas fazendas com auxilio do Povo, segundo o plano, e boa (mutilado) que para este fim se tem pensado alem do (mutilado) de fora. Para o dito efeito se tomarão as medidas... tudo a bem do povo, principalmente a (mutilado) do comercio, e Lavradores taverneiros (mutilada) também serão contemplados na boa união. [sic]

A defesa da propriedade individual se colocava em confronto com a ideia de que o Soberano seria, em última instância, proprietário de todos os bens do reino. Os primeiros teriam os direitos sobre "suas fazendas". E para isso contaria com o apoio do "povo".

No Boletim de número 9 estes elementos são colocados de forma mais clara. O movimento é considerado como uma reação dos "muitos latrocínios", "imposturas", "tributos e direitos que são celebrados por ordem da Rainha de Lisboa". A meta estabelecida seria ir além da eliminação do "péssimo jugo 
reinável da Europa" e de fazer com que o povo ficasse "livre do despotismo do rei tirano".

Uma das primeiras notícias a serem anunciadas pelo governo que se estabeleceria, apontada nesse boletim, seria a implantação de portos abertos a todos os estrangeiros, o que colaboraria para o "progresso do comércio e do Açucar [sic], Tabaco e Pau-brasil e todos os mais gêneros do negócio". Portanto, eliminação do poder despótico no aspecto político com a implementação de uma "República", eliminação do poder despótico no plano econômico com o fim do monopólio de comércio, e o estabelecimento de relações comerciais mantidas através da Igualdade, referida aqui como uma igualdade meramente econômica. Era essa a mensagem anunciada.

A terceira das Décimas sistematiza os efeitos que poderiam ser obtidos com a libertação do jugo colonial. Não de forma explícita, mas utilizando exatamente os mesmos adjetivos citados nos boletins quando referidos à subjugação colonial para abordar os efeitos da Liberdade:

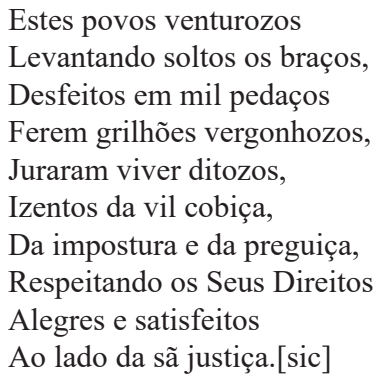

Pode ser observado que alguns termos como "vil cobiça", "impostura" e "preguiça", utilizados para designar as práticas adotadas pelo governo da Coroa Portuguesa, segundo o (s) autor(es) das Décimas, também estavam presentes nos Boletins para caracterizar a situação do Reino português diante da colônia.

$\mathrm{O}$ autor fazia ainda uma alusão à libertação de uma escravidão que pode ter dupla conotação. Contudo, no momento farei apenas referência a um desses sentidos, o mesmo que é colocado pelos Boletins de números 3 e 6. Nestes dois escritos foi assinalado o estado em que estariam prostrados os baianos diante das injustiças cometidas pelo "indigno Coroado". Haveria, pois, a necessidade de libertação do jugo Colonial para que os "baianos" pudessem coexistir ao "lado da sã justiça". Estas colocações são reafirmadas nas primeiras linhas do quarto verso das décimas:

Quando os olhos dos Baianos

Estes quadros divizarem,

E longe de si lançarem 
Mil despoticos tiranos

Quão felizes e soberanos,

Nas suas terras serão! [sic]

Provavelmente, a ideia do momento seria a de vincular o estatuto colonial com o Antigo Regime ou o Regime Absolutista, o que seria uma visão plenamente coerente diante da realidade vivida naquele momento. Seria, portanto, a única maneira de acabar com a desigualdade de privilégios concedida aos reinóis, consequência do status colonial. Nesse sentido, a "Liberdade" do vínculo colonial preconizada pelos revoltosos estaria associada a uma "Igualdade" de condições políticas e econômicas, como pode ser observado em alguns boletins.

\section{Libertação dos Escravos e Igualdade Étnica}

Um segundo tipo de Liberdade e de Igualdade foi abordado nos Boletins Sediciosos e nas Décimas fazendo alusão à escravidão negra e à eliminação da desigualdade étnica. Esteve presente em menor quantidade que a perspectiva anterior, sendo explanada de maneira não tão explícita. Sua identificação é mais clara quando da contraposição desses documentos com os depoimentos presentes nos Autos de Devassa, dados que serão apresentados mais adiante. Mesmo assim é um aspecto que deve ser abordado por sua importância, enquanto proposta contida no projeto de "Revolução". Sobre os Autos de Devassa, o que pode ser antecipado é o fato de terem sido destruídos pelo menos dois boletins que prometiam, explicitamente, a Igualdade entre brancos, pardos e "pretos" bem como a libertação dos escravos, segundo o depoimento de mais de uma das testemunhas arroladas. Sobre os aspectos apontados acima, são relevantes os Boletins de números 1, 9 e 10, bem como os versos 1 e 3 das Décimas.

No Boletim número 1 , temos uma relação daqueles que supostamente estariam seguindo o "partido da liberdade" e onde constavam as funções e ocupações que desempenhavam na sociedade, dentre as quais: militares, membros da administração, homens de letras (intelectuais), homens do comum, comerciantes e religiosos. Não foi feita nenhuma distinção de cor nesta relação e nem mesmo nenhuma citação de escravos que seguissem o movimento. Ora, uma vez que os regimentos militares eram especificados de acordo com a cor de seus membros, seria até mesmo natural que assim o fizessem os boletins, tal como procederam na descrição pormenorizada dos religiosos, indicando a ordem religiosa a que pertenciam aqueles que apoiavam o movimento: Frades Beneditinos, Franciscanos, Terezos, clérigos e Auxiliares do Santo Ofício. Isto, porém, não se apresentou como um elemento de importância para o(s) seu(s) elaborador(es).

Um dado que consta nesses boletins e que, somado ao anterior se torna de 
significativa importância, é que o autor assinalava ao final: "Aqui não se faz menção dos não conhecidos, porém sim daqueles que igualmente se comunicam por conseqüência [sic] da liberdade". Ora, que outro elemento estaria a impedir a comunicação por conta da ausência de liberdade senão a escravidão? É certo que o autor apontava em outros boletins que a sociedade colonial vivia em um estado de constante opressão, e, portanto, de ausência de Liberdade. Mesmo assim, os mais variados grupos constavam na relação citada, salvo os escravos. Além disso, nesses escritos, a cor não se apresentava, segundo entendo, como elemento significativo de diferenciação. Outro elemento que corroboraria essa opinião é o de que, nos preparativos para a tentativa de desencadear o movimento, através da pretendida reunião no Dique do Desterro -em 25 de agosto de 1798-, vários escravos foram aliciados e alguns estiveram presentes. E mesmo nas reuniões efetivadas para a implementação da nova "república" alguns escravos teriam participado, o que caracterizaria o conhecimento acerca desses debates.

Também no Boletim de número 9, uma citação faz alusão à ausência de distinção de cor entre os brancos, pardos e pretos, os três principais grupos étnicos a compor a sociedade colonial. Nesse documento, constava a afirmativa de que os três grupos deveriam concorrer para a "Liberdade popular". O trecho aludia somente aos membros militares das três cores. Porém, esse dado, associado a depoimentos dos Autos de Devassa, também aponta para a tendência a compreender o movimento como antiescravista e marcado por uma pretensão quanto à igualdade entre essas etnias. Mesmo com esta limitação de fazer referência somente aos militares das três "cores", a proposta tem relativa importância dado existirem, neste momento, regimentos e milícias que eram formados apenas por pardos ou apenas por "pretos", sendo de fundamental relevância o apoio destes grupos à causa da "revolução". O boletim de número 10, no entanto, torna mais explícito o motivo dessa convocação e, principalmente, porque estes convocados deveriam aceitá-la:

Portanto invoca a todos aqueles que donde perante que cada hu em partido assim militares, homens pardos e pretos são constantes obem commum da liberdade(...).Cada hu soldado he (mutilado) mormente os homens pardos, e pretos que (mutilada) escornados, e abandonados todos serão iguaes não havera diferença so havera (mutilada) igualdade e fraternidade aquele que seo povo a liberdade Popular serão forçados sem mais apelação: assim seja entendido alias. breve teremos socorro estrangeiro. [sic]

Podem ser observados no trecho acima dois tipos diferenciados de interpretação. O primeiro deles, mais restrito, faz referência à Igualdade de condições e Liberdade para ascensão social de pardos e pretos libertos, mais especificamente àqueles que compunham os quadros militares da Bahia colonial. Assim, o aspecto da contestação à escravidão existente não se apresentaria 
referido. $\mathrm{O}$ que estaria sendo questionado seria o desencontro entre o status social de homens livres que estes possuíam, com a discriminação que sofriam e que lhes restringia à ascensão na escala hierárquica da sociedade baiana.

Uma segunda interpretação, contudo, torna-se viável, e estaria relacionada com a existência, acima citada, de um boletim que se referia explicitamente à libertação dos escravos: a Liberdade e Igualdade prometida para os pardos e "pretos" que participassem do movimento seria a eliminação das diferenças, seria romper, definitivamente, com a condição de "viverem escornados e abandonados", pois, com a revolução "só haverá Liberdade, Igualdade e fraternidade". E, mais adiante, o autor do documento cita que a Liberdade não estaria somente restrita aos militares, mas sim, que seria uma "liberdade popular"18, extensiva a todos os membros da sociedade. A promessa da existência da Fraternidade dentro desta nova sociedade induziria à perspectiva de que a igualdade, ou ainda, uma forma de tratamento não diferenciada em todos os níveis, seria estabelecida.

Nesse sentido, propõe-se fazer uma releitura de determinados trechos de outros boletins, tais como os de números 1, 3 e 9, que confirmariam a amplitude desta segunda interpretação. O estabelecimento da Fraternidade também está referido no boletim de número 1 no seguinte trecho: "está para chegar o Tempo felis [sic] de nossa liberdade: o tempo em que todos seremos irmãos: o tempo em que todos seremos iguais".

A Fraternidade nada mais é, neste sentido, do que ter a perspectiva de que todos os indivíduos da sociedade estavam vinculados através de um pertencimento a uma "família" comum, eliminando as eventuais diferenças que por ventura existissem, o que conduz para uma ideia específica de "Nação" que está por afirmar-se nos anos finais do século XVIII, ao longo da Revolução Francesa ${ }^{19}$.

Em outro trecho do mesmo Boletim, observa-se a convocação de todos para que ressuscitassem "do abismo da escravidão", que pode ser lida como a escravidão social e econômica a que estavam submetidos. No Boletim de número 9 era a escravidão do povo que estava sendo combatida e que era colocada em referência.

\footnotetext{
${ }^{18}$ Essa referência quanto à uma liberdade popular coloca em questão sobre quem seria o "povo" na concepção dos partidários da "revolução" baiana. Uma proposição que pode ser indicada aqui é a de que esse povo era identificado por uma experiência comum que podemos apontar tanto nos Boletins, quanto nas Décimas. Esta experiência era dada pela expectativa por "Liberdade e Igualdade" em diferentes níveis, tais como liberdade comercial, emancipação dos escravos, Igualdade de tratamento entre colonos e metropolitanos, Igualdade étnica e social. Porém, apesar de ocorrer em níveis diferentes, tinham um motivador comum, segundo a compreensão dos participantes do movimento, que era a de que todas as mazelas pelas quais passava a Bahia Colonial eram provocadas pela dominação metropolitana. É esta experiência comum, de viverem sob o signo da opressão e da desigualdade, que os colocava sob a mesma designação de Povo. É justamente por isso que a convocação ocorre objetivando o alcance da fraternidade, de forma que todos os elementos convocados pudessem usufruir das mesmas condições com a efetivação da revolução.
}

19 Anderson, Op. cit., p. 16. 
A consolidação desta segunda interpretação torna-se plausível de duas formas. Numa primeira análise, ao identificarmos que "Povo" é referido nesse momento e, de forma complementar, através da leitura parcimoniosa dos depoimentos constantes nos Autos de Devassa sobre "1798". A segunda opção é a que será desenvolvida aqui, já que o primeiro aspecto apontado não é objeto desse artigo. Porém, antes disso, é importante observar que uma leitura mais atenta das Décimas assinala a possível existência de uma Igualdade dos homens entre si.

Todos os homens apresentariam em si uma mesma essência, resultante de sua origem na criação divina. Justamente por isso, seria direito de todos os homens e de "Deus leis infalíveis", Liberdade e Igualdade. Já a terceira estrofe das Décimas pode indicar na direção de uma proposta de libertação de qualquer tipo de escravidão. Se relacionada com a $2^{a}$ estrofe aponta uma libertação do jugo colonial, uma vez que o levantar de braços desfaria os "grilhões vergonhosos" e os libertaria da vil cobiça, levando-os a formar uma nação tal como os Americanos do Norte e os Franceses. Porém, se relacionada à primeira estrofe leva à possibilidade de vinculá-la à eliminação da escravidão, já que a isenção da "cobiça, da impostura e da preguiça" estaria baseada na igualdade de todos os seres. Ora, se o princípio que justificava a escravidão étnica era justamente a desigualdade entre "brancos, pardos e pretos", a tendência aqui presente nas análises dessa documentação é entender esse trecho como uma apologia, não somente à Liberdade política e Igualdade entre portugueses e colonos, mas também relacionada à Liberdade e Igualdade étnica entre todos os elementos da sociedade baiana, com todos possuindo os mesmos direitos diante da "sã justiça".

\section{Os Autos de Devassa}

Diferentemente do encontrado nos Boletins e nas Décimas, os Autos de Devassa apontam para a tendência a uma inversão quanto à forma de interpretar o que seria Liberdade e Igualdade. A relação que se estabelece aqui é com a possibilidade da emancipação dos escravos e da Igualdade de raças, que se tornam muito mais claras e presentes. Já a relação com a emancipação da metrópole e Igualdade econômica aparece em quantidade muito menor e de forma mais dissipada.

Pode ser apontado também o aparecimento de mais uma forma de interpretação quanto ao que se refere à Igualdade, ainda relacionada com a questão étnica. Ainda que desdobramento da questão escrava, a demanda por igualdade vincula-se à existência de oportunidades sociais semelhantes para pardos e negros libertos. Portanto, seria a Igualdade relativa às condições de ascensão econômica aos pardos dentro da sociedade colonial. 
Nos “Autos de Devassa", a Liberdade relacionada à emancipação colonial da metrópole, não aparece somente associada à Igualdade de tratamento entre colonos e metropolitanos, ou simplesmente em uma Igualdade econômica entre os mesmos. Também aparece vinculada, de forma indireta, com o estabelecimento da Igualdade entre "brancos, pardos e pretos", ou seja, através da Igualdade étnica. Isto é marcante, por exemplo, no depoimento de José Felix $^{20}$, onde este afirma que Lucas Dantas, ao aliciá-lo, considerou que

a causa de quererem reduzida a Republica deste continente era por evitar o grande furto, que o Principe fes a praça desta Cidade, o que bem se conheceo na demora do grande comboi, que ultimamente daqui sahio, ficando os Negociantes a pedirem huma esmola: e que haviao mais de trezentas pessoas a seo partido. [sic]

Nesse sentido, nitidamente uma motivação de tom econômico e que atenderia tão somente àqueles vinculados, seja ao comércio colonial, seja ao comércio interno. Porém, ainda no mesmo diálogo, Felix afirma que Lucas Dantas também fazia referência a outra questão:

E perguntando-lhe elle testemunha (José Felix), que benefício vinha de se levantar este "Brazil em República", lhe respondeu Lucas Dantas que: He para respirarmos livres: pois vivemos sujeitos, e por sermos pardos, não somos admitidos a acesso algum, e sendo Republica, ha igualdade entre todos e a toda esta exhortação ajudava o dito alfaiate Manoel de tal (Faustino), fazendo ver que toda aquella deliberação era justa. [sic]

Mesmo após Lucas Dantas já ter apresentado um motivo para o estabelecimento de um Governo Republicano, independente da Metrópole, José Felix ainda fez a pergunta sobre qual benefício teria ele no estabelecimento de tal governo, o que parece ser um elemento de ativação para a correção da aliciação. Lucas Dantas modificou, então, seu discurso e o direcionou aos interesses do aliciado, afirmando de forma indireta que não somente os negociantes ganhariam, mas também os pardos livres e escravos, pois "sendo Republica, ha igualdade entre todos" [sic].

$\mathrm{Na}$ aliciação feita ao próprio Lucas Dantas, por Antônio Simoens ${ }^{21}$, este afirmava que o movimento consistia em "atacar as Guardas Principaes, desta Cidade, e gritar logo pela voz da Liberdade, afim de se constituir hum Governo Democrático livre e independente." [sic].

\footnotetext{
${ }^{20}$ José Felix: pardo, escravo de Francisco Vicente Vianna. Sabia ler e escrever, mas não possuía ofício certo.

${ }^{21}$ Branco, oficial de pedreiro.
} 
Os Autos, porém, estão mais recheados de exemplos que apontam para a associação do termo Liberdade com a emancipação dos escravos, e do termo Igualdade com a equiparação tanto étnica quanto social entre brancos, pardos e "pretos". Isso é indicado, por exemplo, no depoimento de Ignacio Pires ${ }^{22}$, pardo escravo. Neste, Pires afirmava que para as reuniões para a deliberação do movimento

lá hiam como elle declarante Ignacio dos Santos pardo escravo do Secretário deste Estado José Pires de Carvalho Albuquerque, e Luis de França Pires ${ }^{23}$, escravo do mesmo, posto que participantes do levante não davam parecer sobre elle, e só fallavão na felicidade, e liberdade que delle esperavão. [sic]

Adiante, no depoimento de Ignácio Pires, no qual era solicitado para que especificasse qual felicidade e Liberdade que tanto ele quanto Luís de França Pires esperavam, Ignácio reafirmou a necessidade da presença no Dique do Desterro - local marcado para a verificação da possibilidade de desencadear o movimento -, uma vez que "devia defender o partido da liberdade, em razão de ser elle [sic] cativo, e ter um sobrinho ainda em cativeiro, e que avista disto dicesse [sic] a verdade." De forma mais explícita, nos Autos constam que o convite fora feito para estabelecer um governo de igualdade no qual estaria extinto o cativeiro.

Também no depoimento de Luis Leal ${ }^{24}$, outro pardo escravo, aliciado por Romão Pinheiro ${ }^{25}$, observa-se algo na mesma direção.

Eu e muitos tinhamos determinado fazer hum insulto ou impulso pois (se não lembra de qual das duas expressoens usou) com o qual ficaria muita gente feliz, e porque hum dos chefes desta acção he Luiz Gonzaga ${ }^{26}$, que esta preso nos he precizo adiantar este particular, antes que o dito Gonzaga declare as pessoas que nelle estavão metidas, parte das quaes vivem atemorizadas depois daquella prizão, e por isso andamos convocando alguns sujeitos de capacidade para a dita acção, e porque elle testemunha lhe parecia rapaz prudente e serio, o convidava para a mesma acção, em que podia ser feliz sendo alias cativo. [sic]

Essa proposta antiescravista parece não encontrar tanta resistência entre alguns segmentos de proprietários de terras e escravos, o que pode ser atestado pela rota de fuga de pardos e negros que passaram por terras de Ignácio Bulcão, a presença de Cipriano Barata ${ }^{27}$ no Dique do Desterro e a vinculação de escravos

\footnotetext{
22 Pardo escravo, sem ofício.

${ }^{23}$ Luis de França Pires era pardo escravo com ofício de alfaiate do senhor de engenho José Pires de Carvalho e Albuquerque.

24 Pardo escravo com ofício de sapateiro

25 Soldado.

${ }^{26}$ Soldado pardo. Para alguns autores foi uma das principais lideranças do movimento.

${ }^{27}$ Cipriano Barata de Almeida. Cirurgião, diplomou-se em Coimbra.
} 
de propriedade do Secretário de Estado Pires de Carvalho e Albuquerque nos preparativos para o movimento.

Observe-se, também, a presença de outro motivo que levava, principalmente, aos pardos libertos a lutarem pela mudança do estado das coisas. Esperavam a consolidação efetiva de sua Liberdade e o reconhecimento da Igualdade de condições sociais para todas as "raças" no acesso a "postos e cargos públicos", como no depoimento de Manoel Faustino, onde este afirma:

\begin{abstract}
Perguntado sobre qual a finalidade do Levante, respondeu que "era para reduzir o continente do Brasil a um Governo de igualdade, entrando nele brancos, pardos e pretos, em distinção de cores, somente de capacidade para mandar e governar, saqueando os cofres públicos [sic], e reduzido todos a hum [sic] só, para dele se pagar as tropas e assistir as necessárias despesas do Estado.
\end{abstract}

E no depoimento de Lucas Dantas, quando lhe perguntaram o porquê de ter entrado no movimento, primeiramente afirmou que quem o havia convidado teria sido o soldado Luís Gonzaga das Virgens e Veiga:

\begin{abstract}
porque pelo mes de Novembro o procurara o mesmo Luis Gonzaga na caza delle declarante, juntamente com o Soldado Manoel de Santa Anna, do segundo regimento que dezertou pelas pranchadas, com que foi castigado de Ordem doseo Coronel, e principiara então aexpressar aelle declarante algumas propozicões libertinas e sediciosas, apalpando-lhe o seo animo a esse respeito, e depois o continuara a procurar com repetição, fallando-lhe ja mais claro e persuadindo-o a revolução; fazendo-lhe ver as vantagens de hum governo onde todos figurassem com Igualdade, e o modo, com que isto se poderia conseguir pelo decurso de tempo atrahindo gente a este partido; e que desta maneira ficaria de huma ves desvanecida a differença das cores nos homens, e os pardos habeis para qualquer emprego, ou Dignidade, motivo este que principalmente impellia os seos projetos: que neste mesmo sistema, continuara por todos os mezes seguintes. [sic]
\end{abstract}

João de $\operatorname{Deos}^{28}$ teria aderido ao movimento de forma idêntica, pelos mesmos motivos, como observado abaixo no depoimento de Manoel Faustino na qual aponta como aliciador a Lucas Dantas:

Perguntado se sabe quem convidou a Jõao de Deos para esta conjuração? Dice que estando elle declarante em certa occazião na casa de Lucas Dantas ahi foi ter João de Deos a fallar-lhe sobre um pau, que lhe tinha encomemdado; convidando o dito Lucas Dantas, ao mesmo João de Deos para huma função, sem que lhe declarasse qual era; a força da instancia do dito João de Deos, o mesmo Lucas lhe declarou ser o levante, e conjuração que estava projetada a fim de reduzir este Continente a hum Governo de igualdade, e não se lembra elle declarante o que mais dicerão elles de parte. [sic]

${ }^{28}$ Pardo alfaiate, tido como uma das lideranças, foi enforcado e esquartejado. 
Todos os pardos libertos citados estavam interessados, principalmente, na possibilidade de ascender a postos e cargos públicos, o que lhes era vedado pela condição de cor que estes estampavam em suas peles. Havia uma compressão clara de que sua liberdade não seria completa, e de que as coisas somente mudariam de forma satisfatória com a formação de um governo Republicano, onde todos os elementos da sociedade se apresentassem como "irmãos", ou ainda, onde todos seriam "iguais". Neste sentido, não bastava estabelecer a libertação dos escravos, mas, antes de tudo, seria primordial mudar também a forma de governo e a estrutura da sociedade, eliminando de vez as restrições raciais e sociais contra pardos e "pretos".

\section{Liberdades, Igualdades e a "revolução Bahiana"}

Pode ser afirmado, inicialmente, que os termos Liberdade e Igualdade foram ideias extremamente propagadas não somente na Revolução Francesa. Igualmente, ao longo das diversas reuniões ocorridas na Bahia sediciosa, não por mera influência, essas ideias representaram a verdadeira possibilidade de transformação e reconfiguração da sociedade, até então baseada no pressuposto do reino dinástico rigidamente hierarquizado.

As sociedades de Antigo Regime eram caracterizadas por elementos de continuidade e transição. Um aspecto de continuidade estava demarcado pela presença da desigualdade inerente aos indivíduos, oriunda da origem de nascimento. Em uma sociedade colonial, a origem étnica apresentava-se como um elemento ratificador dessas desigualdades.

Mas também pode ser indicado que o aparecimento de novas referências de organização social teve curso naquele momento. Algumas perspectivas do Iluminismo retrataram, no âmbito das ideias, esta transformação. As mudanças nas concepções das noções de Liberdade e Igualdade indicaram esse reordenamento da sociedade, pensado de diferentes formas pelos agentes envolvidos nos embates políticos daquele momento, tal qual observado na França Revolucionária.

Em uma sociedade colonial como a Bahia de fins do XVIII, marcada pela presença da escravidão e pelo domínio metropolitano, essas ideias apresentaram novas reconfigurações. Não a proposta de uma sociedade desprovida de hierarquia, mas sim, fundamentada em novos princípios hierarquizantes. As análises acerca da Conjuração Baiana apontam para a presença de três sentidos diferentes.

É encontrada uma concepção de Liberdade marcada pela eliminação de barreiras econômicas e políticas, representação esta que, tendencialmente, pode ter sido elaborada pela elite econômica da colônia. Essa ideia de liberdade 
apresentava-se associada a uma concepção de "Igualdade", percebida como obtenção de mesmas condições no tratamento a nível econômico entre colonos e metropolitanos, ou ainda, entre baianos e as nações que se dispusessem a comercializar com eles.

Outra perspectiva de "liberdade", elaborada naquele momento, caracterizou-se pela possibilidade de acesso social, de acordo com a capacidade de fazer e realizar de cada um na hierarquia baiana. Essa percepção de liberdade vinculava-se, por sua vez, a uma "igualdade" específica, compreendida como iguais condições para cada indivíduo acender na hierarquia social. Esses aspectos atendiam diretamente aos pardos e "pretos" libertos da sociedade baiana.

Por último, observa-se uma percepção de liberdade enquanto emancipação dos escravos. Atendia, principalmente, aos anseios da massa de africanos, quer tivessem chegado recentemente ou não. No entanto, ainda seja observada essa diversidade de interpretação, em todas percebe-se a presença de um denominador comum: o fim do jugo colonial.

Efetivamente, não pode ser afirmado que cada grupo elaborou "per si" essas representações de acordo com seus próprios interesses. Mais difícil ainda é a concepção de que um único grupo tenha elaborado todas as representações. O que busco apresentar é a existência dessas diferenças, entendendo que, na medida em que o ideário ia sendo divulgado, foram se consolidando na efetivação de cada aliciamento, mescladas entre si.

Pode ser afirmado, ainda, que a identificação do poder metropolitano como principal responsável pela opressão que estimulava as demandas por igualdades e liberdades contribuiu, fundamentalmente, para que a conjura se apresentasse com uma configuração social e étnica extremamente diversificada. Os conflitos existentes no âmbito interno da sociedade colonial -entre senhores de escravos e escravos-, e a limitação na possibilidade de ascensão social para pardos e negros libertos se apresentaram como problemas a serem ultrapassados pela superação das contradições existentes no âmbito externo: o domínio colonial. Foi isso que uniu os distintos interesses presentes dentre os "revolucionários" baianos em torno de uma transformação efetivamente "revolucionária" para fins do século XVIII. 


\section{Referências Bibliográficas}

Amaral, Braz. Os confederados do Partido da Liberdade. Salvador: Imp. Oficial, 1922.

Anderson, Benedict. Nação e consciência nacional. São Paulo: Ed. Ática, 1989. Guinsburg, Carlo. O Queijo e os Vermes - cotidiano e as ideias de um moleiro perseguido pela inquisição. Rio de Janeiro: Cia das Letras, 1987.

. "Chaves do Mistério: Morelli, Freud e Sherlock Holmes", in: Eco, Umberto e Sebeok, Thomas A.(org). O Signo de Três. São Paulo: Ed. Perspectiva, 1991.

Hobsbawn, Eric. Nações e nacionalismo desde 1780: programa, mito e realidade. Rio de Janeiro: Editora Paz e Terra, 1990.

Jancsó, Itsvan. Na Bahia, contra o Império: história do ensaio de sedição de 1798. São Paulo: Ed. Hucitec, 1996.

Matoso, Kátia de Queiroz. Presença francesa no movimento democrático baiano. Salvador: Ed. Itapuã, 1969.

Mattos, Florisvaldo. A comunicação social na Revolução dos Alfaiates.Bahia: Imp. Oficial, 1974. (Coleção Estudos Baianos).

Motta, Carlos Guilherme. Ideia de revolução no Brasil: 1789-1801. São Paulo: Ed. Cortez, 1989.

Ruy, Afonso. A primeira revolução social brasileira. Salvador: Ed. Progresso, 1995.

Tavares, Luís Henrique. História da Sedição Intentada na Bahia de 1798. São Paulo: Ed. Pioneira/ Brasília: Instituto Nacional do Livro, 1975. . Da Sedição de 1798 à Revolta de 1824 na Bahia.

Salvador: EDUFBA; São Paulo: Unesp, 2003.

Thompson, E. P.. A formação da Classe Operária Inglesa - A Árvore da Liberdade. Rio de Janeiro: Ed. Paz e Terra, 1987.

\section{Documentos impressos}

A Inconfidência da Bahia - Devassas e Sequestros - volumes I e II. Rio de Janeiro: Officinas Graphicas da Biblioteca Nacional, 1931. Extraída dos vols. XLIII, XLIV e XLV dos Anaes da Biblioteca Nacional.

\section{Documentos Manuscritos}

Boletins Sediciosos. Biblioteca Nacional, Seção de Manuscritos, I - 28, 23 / n. 1-12, cópia dos originais. 
